\title{
World Digestive Health Day - WDHD Poland 2017 Inflammatory Bowel Diseases - Challenges and Hopes
}

\author{
Wojciech Marlicz \\ Department of Gastroenterology, Pomeranian Medical University, Szczecin, Poland
}

Gastroenterology Rev 2018; 13 (1): 82-84

DOI: https://doi.org/10.5114/pg.2018.74729

The Polish Society of Gastroenterology (PSG) was the first gastrointestinal (GI) subspecialty society in Europe, created in 1909, only a few years after the formation of the American Gastroenterological Association (AGA) and the Japanese Society of Gastroenterology (JSG). Polish GI physicians were always a part of the international family of gastroenterologists. Polish doctors who made a significant contribution to the world of medicine include Jan Mikulicz-Radecki - the founding father of Gl endoscopy, Ludwik Rydygier - one of the most famous gastric surgeons, and Walery Jaworski - professor at Jagiellonian University in Krakow, who discovered the spiral bacteria in the stomach, named Helicobacter pylori (H. pylori) 100 years later [1]. Among them was also Prof. Antoni Lesniowski, who first described the unspecific inflammation of terminal ileum and did it many years before Dr Burbill Crohn [2].

Inflammatory bowel disease (IBD) is an umbrella term for chronic Gl pathologies comprising ulcerative colitis (UC), Crohn's disease (CD), and microscopic colitis (MC) [3].

The prevalence of IBD worldwide is on the rise, becoming a global disease emergence and one of the most important medical problems in modern medical practice. In Poland, the number of CD patients registered in the Polish Registry of Crohn's disease exceeds 6600 cases [4]. However, the true estimates are that there are more than 15 thousand CD and 40 thousand UC sufferers in Poland. The majority of patients, mostly below the age of 35 years, are at life-long risk of developing complications and disability while carrying the disease. Modern disease management should be multidisciplinary, and include medical practitioners of various fields - gastroenterologists, Gl surgeons, dietitians, clinical pharmacists, physiotherapists, psychologists, and caregivers. Patients' societies also have the power to change medical paradigms and influence institutions, health decision makers, and other patients as well.

The Polish Society of Gastroenterology as a member and partner of the World Gastroenterology Organisation (WGO) aims to raise awareness of IBD through an annual WGO public advocacy and awareness campaign:
World Digestive Health Day (WDHD). WDHD is celebrated each year with associated activities and initiatives continuing throughout and beyond the campaign year. The WDHD campaign seeks to translate research into clinical practice and facilitate communication between physicians, pharmacists, allied health professionals, healthcare payers, and the public. The aim of the WGO is to ensure that awareness of the disease and its management is raised in countries where IBD is increasingly and newly diagnosed [5].

Therefore, this year the teams of the Department of Gastroenterology of Pomeranian Medical University in Szczecin, the Polish Celiac Society, and the European Lifestyle Medicine Organisation (ELMO) together with the Polish Society of Gastroenterology, under the auspices of the World Gastroenterology Organisation (WGO), on May 13, 2017 in Szczecin, Poland, organised a WDHD Conference titled: IBD - Challenges and Hopes. Numerous prestigious collaborators joined the Polish WDHD campaign: West-Pomeranian Divisions of the Polish Society of Gastroenterology and Polish Society of Surgeons, Collegium of Family Physicians in Poland, Polish Society for Parenteral, Enteral Nutrition, and Metabolism (POLSPEN), and Divisions (Warsaw and Szczecin) of the International Federation of Medical Students' Associations IFMSA-Polska and Associations of Patients - "J-elita" (Polish Association Supportig IBD Patients) and "Appetite for Life" (Associations of patients with disabilities of digestive system with special attention to persons, who require special and chronic enteral and parenteral nutrition). We were also proud to have the support of one of the biggest social and media IBD campaigns in Poland - flakirozrabiaki.org - supported by famous celebrities - Agata Młynarska among them.

Notable governmental bodies and scientific institutions welcomed our invitation to serve as Honorary Patrons: City Council Szczecin, the Presidents of Pomeranian Medical University and West Pomeranian University of Technology, Regional Chamber of Physicians, Regional Chamber of Nurses and Midwifes, West Pomeranian Chamber of Pharmacies, Polish Society of Laboratory Diagnostics, West Pomeranian Divisions of Polish 


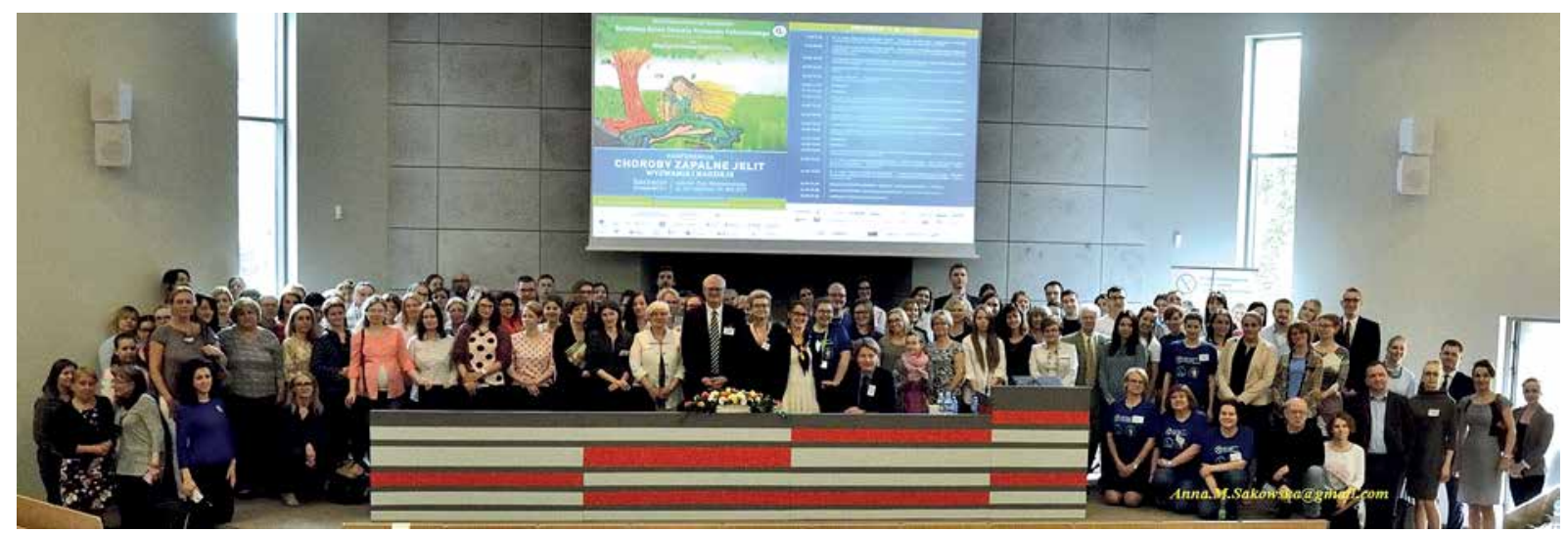

Figure 1. World Digestive Health Day 2017 Poland “Inflammatory Bowel Diseases - Challenges and Hopes"

Society of Pharmacology, and the Polish Pharmaceutical Society. Important topics related to IBD were highlighted during the conference - diagnostic dilemmas, management, prognosis, and quality of life. The importance of prevention, prophylaxis, and lifestyle- habits (e.g. nutrition, physical activity, stress management) in IBD were discussed.

The WDHD event gathered more than 300 participants. Key opinion leaders delivered state-of-the-art lectures. Special attention was paid to the role of nutrition (clinical and outpatient), intestinal microbiota, and autoimmune comorbidities such as celiac sprue, and Hashimoto's or rheumatic disease.

Dr. Wojciech Marlicz (Department of Gastroenterology, PUM, Szczecin) delivered the opening lecture titled "Inflammatory Bowel Diseases - challenges and hopes". Dr. Marlicz discussed the difficulties in translating science from bench to bedside. Clinical uncertainties were also debated [6]. Dr. Marlicz expressed the opinion that new research fields of microbiome, -omics, stem cells, and e-health will lead us towards personalised medicine in the near future. The next lecture was presented by Prof. Grażyna Rydzewska, President of the Polish Society of Gastroenterology (Department of Gastroenterology, Central Hospital, Warsaw). In her lecture titled "The role of general practitioner in the management of patients with IBD" Professor Rydzewska talked about new recommendations issued by the Polish Society of Gastroenterology on IBD management in the practice of general practitioners (GPs) [7, 8]. Prof. Ewa Stachowska (Department of Biochemistry and Human Nutrition, PUM, Szczecin) taught us what to eat and which food to avoid in order to maintain a healthy gut in the lecture "Feed your microbiome". Marek Witkowski (Euroimmun Polska) discussed the problems of monitoring celiac patients on a gluten-free diet. Mrs. Jolanta Meller (Polish Celiac Society, Szczecin) convinced us that "Drop drills the rock". Her lecture showed that persistence pays off, with the Polish Celiac Society as a great example of robust growth in recent years.

Professors Teresa Starzyńska and Dariusz Bielicki (Department of Gastroenterology, Pomeranian Medical University in Szczecin) informed us through their lecture "Chronic diarrhoea - differential diagnosis based on clinical case presentation" that maladies other than IBD can be the cause of chronic diarrhoea. Anna Żuk, MSc, clinical nutritionist (Silesian Medical University in Katowice) in her lecture "Clinical nutrition - in an eye of the hospital pharmacist" showed how to act professionally with regard to clinical nutrition. The next lecture was delivered by Marek Lichota, the founder and president of the Appetite for Life association. In his very challenging lecture, Mr. Lichota gave an excellent overview on the role of associations of patients suffering from digestive diseases with the need for special nutritional requirements. Mr. Lichota, as a Crohn's patient, has a life-long need for parenteral nutrition. His speech, similarly to Nick Vujicic's emotional talk, was full of motivation, which every person with IBD needed. Next, Łukasz Fraszka (ALAB) talked about the value of stool calprotectin testing in everyday medical practice. Zuzanna Jankiewicz (Twisted Cafeteria - Lab of Healthy and Artistic Pastries) called for elimination diets - "Elimination diet, why not?". After a break the conference was continued by distinct speakers.

Dr. Katarzyna Fischer (Diagnostic Rheumatology Lab, Pomeranian Medical University in Szczecin) discussed the role of serological tests in the diagnosis of IBD. Our conference could not be organised without also hearing from our leading scientist, Dr. Karolina Skonieczna-Żydecka (Department of Biochemistry and Human Nutrition, PUM). In a very innovative way Dr. Skonieczna-Żydecka introduced the audience to the topic "Gut barrier - the role in the pathogenesis, diagnosis, and therapy of functional gastrointestinal disorders", in which the mechanisms of interplay between 
environmental factors and gut microbiota, neuroimmune, and hormonal systems were discussed. The next lecture was presented by Dr. Romana Kosik-Warzyńska (J-elita, Szczecin). Dr Kosik-Warzyńska discussed novel therapies available for IBD patients in Poland. Anna Prawdzic-Wondek (SANPROBI) lectured about the benefits of probiotics. Last but not least, we heard from our famous blogger Weronika Madejska, who took us on a journey with "no gluten, no cry". Her personal success on the field of disease battles are popular topics on her internet blog at natchniona.pl. Weronika passionately offers healthy dietary recipes to IBD communities.

The media patrons of the Conference were: Polish GI Medical Journal - "Gastroenterology Review", Termedia, Food Forum, Dietetycy, Spozywo, and Med Tube. After the final lecture, a group photo was taken (Figure 1). World Digestive Health Day 2017 was free of charge. Significant efforts were made to distribute posters, leaflets, and invitations. Participants of the conference were invited to taste a wide range of healthy and ecological food offered by local manufacturers. The members of the Polish Society of Gastroenterology are looking forward to continuing collaboration with the World Gastroenterology Organisation for the benefit of all our patients.

\section{References}

1. Marlicz W. Let's Talk About the Gastroenterology Practice in Poland. AGA Perspectives, 10 Nov 2011.

2. Bielecki K. Professor Antoni Leśniowski (1867-1940) and his contribution to the history of Crohn's disease. Prz Gastroenterol 2011; 6: 57-9.

3. Eisenstein M. Biology: a slow-motion epidemic. Nature 2016; 540: S98-99.

4. http://www.chorobacrohna.pl

5. http://www.worldgastroenterology.org/wgo-foundation/wdhd/ wdhd-2017/message-from-the-chair

6. Marlicz W, Yung DE, Skonieczna-Zydecka K, et al. From clinical uncertainties to precision medicine: the emerging role of the Gut barier and microbiome in small bowel functional diseases. Expert Rev Gastroenterol Hepatol 2017; 11: 961-78.

7. Golik M, Kurek M, Poteralska A et al. Working Group Guidelines on the nursing roles in ca ring for patients with Crohn's disease and ulcerative colitis in Poland. Prz Gastroenterol 2014; 9: 179-93.

8. Gonciarz M, Szkudłapski D, Mularczyk A, et al. Wytyczne postępowania z chorymi na nieswoiste choroby zapalne jelit w praktyce lekarza rodzinnego. Lekarz POZ 2017; 3: 1-11. 